\title{
Exposure to diesel exhaust during fetal period affects behavior and neurotransmitters in male offspring mice
}

\author{
Satoshi Yokota1,3, Nozomu Moriya², Mari Iwata', Masakazu Umezawa³, Shigeru Oshio ${ }^{4}$ \\ and Ken Takeda ${ }^{1,3}$ \\ ${ }^{1}$ Department of Hygiene Chemistry, Faculty of Pharmaceutical Sciences, Tokyo University of Science, \\ 2641 Yamazaki, Noda-city, Chiba 278-8510, Japan \\ ${ }^{2}$ Department of Biopharmaceutics, Hyogo University of Health Sciences, \\ 1-3-6 Minatojima, Chuo-ku, Kobe, Hyogo, 650-8530, Japan \\ ${ }^{3}$ The Center for Environmental Health Science for the Next Generation, Research Institute for Science and \\ Technology, Tokyo University of Science, 2641 Yamazaki, Noda-city, Chiba 278-8510, Japan \\ ${ }^{4}$ Department of Hygiene Chemistry, School of Pharmaceutical Sciences, Ohu University, 31-3 Misumido, Tomita-cho, \\ Koriyama-city, Fukishima 963-8611, Japan
}

(Received October 4, 2012; Accepted October 31, 2012)

\begin{abstract}
Exposure to ambient particulate matter (PM) has been associated with the onset of cardiovascular and respiratory diseases. Diesel exhaust particles (DEP) are major components of ambient PM. We first reported DEP in the central nervous system of offspring utilizing maternal inhalation to diesel exhaust (DE). In addition, we found that the effects of maternal exposure to DE reduced spontaneous motor activity. However, it is still unknown whether maternal exposure to DE affects higher order behavioral function. Therefore, the aim of the present study was to examine the effects of fetal exposure to $\mathrm{DE}$ on motor coordination, impulsive behavior and monoaminergic systems in various brain regions. The results of the rotating rod test showed that DE-exposed mice displayed decreased time on the rota rod compared to control mice. However, no changes were detected between the two groups in the hanging test. Furthermore, the cliff avoidance test revealed that DE-exposed mice spent more time in the corner and fell off an inverted glass beaker compared to control mice. High performance liquid chromatography analysis revealed that noradrenaline turnover in the cerebellum was decreased by prenatal exposure to $\mathrm{DE}$, and was significantly increased in the hypothalamus. Dopamine and serotonin levels in various brain regions were also changed by prenatal exposure to DE. Our study found that prenatal exposure to $\mathrm{DE}$ alters motor coordination, impulsive behavior and related monoamine levels. Therefore, the present study underscores the role of behavioral changes related to monoamine in response to maternal inhalation of DE.
\end{abstract}

Key words: Fetal period, Diesel exhaust, Air pollutants, Central nervous system, Motor coordination, Impulsive behavior

\section{INTRODUCTION}

Numerous studies have indicated a causal relationship between ambient particulate matter (PM) in metropolitan areas and health risks (Pope, 2004). Recently, attention has focused on the effects of ultrafine particles or nanoparticles $(<100 \mathrm{~nm}$ ) (Oberdörster et al., 2005; Nel et al., 2006). Diesel exhaust (DE) is composed of gaseous compounds and particulate matter defined as diesel exhaust particles (DEP). DEP emmitted from diesel engines are the largest contributor of airborne PM, and DEP can persist in the air where these compounds are readily inhaled. Therefore, the effects of exposure to DE represent a significant concern for healthcare.

While most studies of the toxicological effects of air pollution have focused on cardiovascular and pulmonary functions (Campen et al., 2010; Ichinose et al., 1997), more recent studies have examined the effect of air pollution on the central nervous system (CNS) (Block and Calderón-Garcidueñas, 2009). In fact, the effects of expo-

Correspondence: Satoshi Yokota (E-mail: j3109705@ed.noda.tus.ac.jp) 
sure to DE and DEP on the CNS have been reported in several epidemiological studies. One of these studies found a potential adverse effect of air pollutants in Mexico City on the CNS of dogs (Calderón-Garcidueñas et al., 2002). In humans, a subsequent study showed neurobehavioral and pulmonary impairment in railroad workers and electricians (Kilburn, 2000). Furthermore, X-ray fluorescence analysis in a kinetics report revealed that metal elements of DEP, which contained nano-sized particles, were detected in the olfactory epithelium and bulb of mice (Matsui et al., 2009).

Several experimental studies have been performed to evaluate the mechanisms underlying the effects associated with exposure to DE on the CNS. To date, the molecular mechanisms were primarily attributed to inflammation mediated by oxidative stress. The inflammatory effects of DEP appear to be driven by the particulate component such as the surface area effect (Heinrich et al., 1995). However, the organic and metal components also appear to play a role in oxidative and proinflammatory effects related to pathogenicity (Gnoth et al., 1999; Ball et al., 2000). DEP are composed of a carbonaceous core with adsorbed organic compounds, sulfates, and trace elements (Umezawa and Takeda, 2011). Soluble organic compounds, including polycyclic aromatic hydrocarbon (PAH), can represent up to sixty percent of the mass of the DEP particle. PAH resemble steroid hormones, and can elicit estrogenic and antiestrogenic activity (Santodonato, 1997). The effects of perinatal exposure to DE on the expression levels of estrogen receptors of the cerebrum of a neonate was previously reported (Tsukue et al., 2009). The literature has established that estrogen is modulate brain development, neuroprotection as well as the regulation of monoaminergic systems (McEwen and Alves, 1999).

Evidence indicates that environmental exposure in utero and during early life can permanently change the body's structure, physiology and metabolism, and this exposure can lead to diseases in adults (George et al., 2009). Due to unprotected barriers in the CNS and developmental plasticity influenced by the environment, a long period of vulnerability in the developmental process exists that increases the susceptibility of the CNS to environmental insult (Landrigan et al., 2005). For instance, a previous report found that in utero exposure to DEP decreased weight gain during lactation (Hougaard et al., 2008). In our previous study using a mouse model, caspase 3-positive cells were increased in the cerebellum by prenatal exposure to DE, a structure that regulates motor coordination (Sugamata et al., 2006b). In addition, serum testosterone concentration, a parameter of impul- sive behavior such as aggression, was also increased by maternal exposure to DE (Yoshida et al., 2006). Furthermore, we showed that prenatal exposure to DE decreased locomotion as well as dopamine metabolites in the nucleus accumbens (Yokota et al., 2009), which was confirmed in a subsequent study (Suzuki et al., 2010).

However, it is not known whether the changes in higher order behavior (i.e., motor coordination and impulsive behavior) are induced by maternal exposure to DE. In the present study, we hypothesized that monoamine levels would be altered in specific brain regions following maternal exposure to DE. Therefore, the aim of the present study was to examine the effects of prenatal exposure to DE on motor coordination and impulsive behavior. Following the behavioral testing, we also assessed monoaminergic systems in various brain regions considered to be related to these behavioral changes.

\section{MATERIALS AND METHODS}

\section{Animals}

Pregnant ICR mice at gestational days (GD) 1 were purchased from Japan SLC Inc. (Shizuoka, Japan). The mice were divided into two groups: (1) diesel exposure group $(n=15)$ and (2) control group $(n=15)$. The two groups of mice were housed in separate inhalation chambers, and were housed under controlled conditions with $12 \mathrm{hr}$ light/12 hr dark cycle and ad libitum access to food and water. The mice were exposed to diesel exhaust for $8 \mathrm{hr} /$ day (9:00-17:00) for five days per week in the inhalation chambers at the Research Institute of Tuberculosis (Japan Anti-Tuberculosis Association, Tokyo, Japan) from GD 2 to 17. Pregnant mice were housed in stainless steel wire mesh cages during the exposure period; postpartum offspring would immediately drop away from the cages. GD 17 is considered to be the end of teratogenic period in mice; hense, the designated exposure period was from GD 2 to 17 . After this period, mothers and pups were maintained in a clean room. On postnatal day (PND) 7, the number of pups per litter was adjusted to ten. The pups were weaned on PND 21, and male mice were then transported to Tokyo University of Science (Chiba, Japan). Mice were transported carefully to minimize stress factors by Sankyo Labo Service Co., Inc. (Tokyo, Japan) and Tokyo Laboratory Science Co., Ltd. (Tokyo, Japan). Experiments were approved by institutional and national guidelines for the care and use of laboratory animals.

\section{Diesel exhaust exposure}

A 2369 cc diesel engine (Isuzu Motors Ltd., Tokyo, 
Fetal exposure to diesel exhaust affects behavior in male mice

Japan) was operated at a speed of 1,050 rpm and at $80 \%$ load with a commercial oil. The exhaust was introduced into a stainless steel dilution tunnel (450 mm diameter $\times$ $6,250 \mathrm{~mm}$ ) where the exhaust was mixed with clean air. The average concentrations of exhaust constituents were maintained at $1.0 \mathrm{mg} / \mathrm{m}^{3}, 2.67 \mathrm{ppm}$ for carbon monoxide (CO), $0.23 \mathrm{ppm}$ for nitrogen dioxide $\left(\mathrm{NO}_{2}\right)$, and less than $0.01 \mathrm{ppm}$ for sulfur dioxide $\left(\mathrm{SO}_{2}\right)$.

\section{Behavioral analysis}

The rotating rod test, the hanging test, and the cliff avoidance test were performed as previously described (Shimizu et al., 2002; Matsuoka et al., 2005). The rotating rod test and the hanging test were performed when offspring male mice were five weeks old. Motor coordination was assessed with a rotating rod apparatus (ENV-576 Mouse Rota Rod Single Station, MED Associates Inc., St. Albans, VT, USA), which consisted of a plastic rod (3 $\mathrm{cm}$ diameter, $8 \mathrm{~cm}$ long) with a gritted surface flanked by two large discs (40 cm diameter). The mice were placed on the rod, and the rod was rotated at a speed of 0 (stationary) rpm, $4 \mathrm{rpm}$, and $16 \mathrm{rpm}$. Three trials were conducted at each speed except for the stationary. Latency was monitored for $120 \mathrm{sec}$ or until a fall occurred. Intratrial intervals for each animal were more than $20 \mathrm{~min}$. In the hanging test, a mouse was placed on the stainless bar (50 cm length, $2 \mathrm{~mm}$ diameter, elevated $37 \mathrm{~cm}$ from a surface) at a point midway between the supports, and was observed for $30 \mathrm{sec}$ in four separate trials. The amount of time spent hanging was recorded. Cliff avoidance tests were performed when male offspring were six weeks of age. Cliff avoidance, defined as not jumping from the platform, were evaluated with the use of a round platform (an inverted glass container with a diameter of $13 \mathrm{~cm}$ and height of $20 \mathrm{~cm}$ ). For this test, the mice were placed on the platform, and behaviors were video recorded for $10 \mathrm{~min}$.

\section{Sampling procedure}

Brains in anesthetized male offspring mice were isolated at three and six weeks of age, respectively. No differences were observed in body weight between the expo- sure group and the control group (Table 1). The brains were dissected into various regions required for monoamine analysis. The brain regions were frozen in liquid nitrogen, and stored at $-80^{\circ} \mathrm{C}$ until use.

\section{Brain dissection}

Brain dissection was performed according to the modified method of Heffner et al. (1980), and was based on the atlas described by Paxinos and Franklin (Paxinos and Franlin, 2001). The following brain regions were rapidly dissected from coronal brain sections: (1) prefrontal cortex (containing cingulated cortex and motor cortex areas 1 and 2), (2) striatum, (3) hippocampus, (4) amygdala, (5) hypothalamus, (6) cerebellum and (7) brainstem. Determination of monoamine levels was conducted in the prefrontal cortex, striatum, hippocampus, hypothalamus, amygdala, cerebellum and brainstem.

\section{Neurochemical analysis}

Frozen brain tissues were homogenized in ice cold 0.2 M perchloric acid (Nacalai Tesque Inc., Kyoto, Japan) containing $100 \mathrm{mM}$ EDTA 2Na (Dojindo Laboratories, Kumamoto, Japan) and $100 \mathrm{ng}$ isoprotenol (SigmaAldrich Co., St. Louis, MO, USA), as an internal standard. The homogenates were centrifuged at 20,000 $\times \mathrm{g}$ for $15 \mathrm{~min}$ at $0^{\circ} \mathrm{C}$. Supernatants were transferred to new tubes, and the pellets were stored for protein assay. The $\mathrm{pH}$ of the supernatant was adjusted to 3.5 with $1 \mathrm{M}$ sodium acetate (Kanto Chemical Co., Inc., Tokyo, Japan), and stored at $-80^{\circ} \mathrm{C}$ until analysis. For HPLC, $10 \mu \mathrm{l}$ of the $\mathrm{pH}$ adjusted supernatant was injected with a microsyringe (702SNR; Hamilton Co., Reno, NV, USA) into an HPLC system with electrochemical detection (HTEC-500MAB; EICOM Co., Kyoto, Japan). Each group contained samples from nine mice. The standard solution contained the monoamines dopamine (DA) and noradrenaline (NA) as well as serotonin (5-HT) and their metabolites. The DA metabolites were 3-methoxytyramine hydrochloride (3-MT), 3,4-dihydroxyphenylacetic acid (DOPAC) and homovanillic acid (HVA). The NA metabolites were normetanephrine hydrochloride (NM) and 4-hydroxy-3methoxyphenylglycol hemipiperazinium (MHPG). The

Table 1. Body weights of mice at three and six weeks old

\begin{tabular}{lcccccc}
\hline & \multicolumn{3}{c}{3 weeks } & & \multicolumn{2}{c}{6 weeks } \\
\cline { 2 - 3 } \cline { 5 - 6 } & Control & 10 & DE & & Control & DE \\
\hline Number & $20.5 \pm 1.2$ & $21.8 \pm 0.8$ & & $40.0 \pm 1.2$ & $42.5 \pm 1.3$ \\
Weight $(\mathrm{g})$ & & &
\end{tabular}

The data were presented as the mean \pm S.E. of ten mice. 


\section{S. Yokota et al.}

5-HT metabolites were 5-hydroxyindole-3-acetic acid (5-HIAA). Standards DA, HVA, 3-MT, NM, MHPG, 5-HT and 5-HIAA were obtained from Sigma-Aldrich. Standards NA and DOPAC were obtained from Nacalai Tesque and Wako Pure Chemical Industries, Ltd. (Osaka, Japan), respectively. The monoamines and their metabolites were separated by passage through a $\mathrm{C} 18$ reverse-phase column (Eicompak SC-5ODS; $3.0 \mathrm{~mm} \times 150 \mathrm{~mm}$; Eicom) maintained at $25^{\circ} \mathrm{C}$ and connected to an electrochemical detector (EPC-500, Eicom). The mobile phase was $0.1 \mathrm{M}$ acetic acid/citric acid buffer ( $\mathrm{pH}$ 3.5) containing EDTA 2Na (5 mg/l), sodium 1-octanesulfonate (190 mg/l; Nacalai Tesque), and 15\% methanol (Kanto Chemical Co., Inc.). The flow rate was maintained at $0.5 \mathrm{ml} / \mathrm{min}$ for $35 \mathrm{~min}$. Data were collected and analyzed with the PowerChrom 280 System (eDAQ Pty Ltd., New South Wales, Australia). To determine the protein concentration, the pellets were dissolved in $100 \mathrm{mM}$ Tris- $\mathrm{HCl}$ for protein determination by a high sensitivity version of the Bradford method with a commercial reagent (ADV-01; Cytoskeleton Inc., Denver, CO, USA), and measurements were performed according to the manufacturer's protocol. The absorbance was measured at $595 \mathrm{~nm}$ with a 96 well microplate reader (model 550; Bio-Rad Laboratories Inc., Hercules, CA, USA), and protein concentration was calculated from a standard curve generated with bovine gamma globulin (Pre-Diluted Protein Assay Standards: Bovine Gamma Globulin Set; Thermo Fisher Scientific Inc., Rockford, IL, USA). Concentrations of monoamines and their metabolites are expressed as $\mathrm{pg} / \mathrm{mg}$ of protein, and the catabolism rate is expressed as the ratio of metabolite to monoamine (e.g. MHPG/NA).

\section{Statistical analysis}

Data from the rotating rod test and hanging test were analyzed using a two-way analysis of variance (ANOVA) with repeated measures for the trials. The remaining data were analyzed by the Mann Whitney U-test. Data were expressed as mean \pm S.E. Differences between groups were examined for statistical significance, and $\mathrm{P}<0.05$ and $\mathrm{P}<0.01$ indicate statistical significance.

\section{RESULTS}

\section{Behavioral analysis (Rotating rod test, Hanging test, Cliff avoidance test)}

To assess the motor function of offspring male mice, the rotating rod test and hanging test were performed. The rotating rod test was performed at five weeks of age. In this test, the rodents were exposed to three variations of speed ( $0 \mathrm{rpm}, 4 \mathrm{rpm}, 16 \mathrm{rpm})$, and the test was per- formed in three separate trials at $4 \mathrm{rpm}$ and $16 \mathrm{rpm}$. In the stationary phase $(0 \mathrm{rpm})$, no differences were detected in latency time to fall off in the maternally DE exposed group compared to controls. However, the retention time of DE exposed mice on the rod was significantly shorter than that of controls at both $4 \mathrm{rpm}$ and $16 \mathrm{rpm}$ [4 rpm: $\mathrm{F}(1,84)=10.16 ; \mathrm{P}=0.002 ; 16 \mathrm{rpm}: \mathrm{F}(1,84)=10.90$; $\mathrm{P}=0.001]$ (Fig. 1A). While learning effects of both control and DE exposed mice were observed at every speed [4 rpm: $\mathrm{F}(2,84)=3.41 ; \mathrm{P}=0.038 ; 16 \mathrm{rpm}: \mathrm{F}(2,84)$ $=6.50 ; \mathrm{P}=0.002]$, no exposure $\times$ trials interaction was detected using a two-way analysis of variance (ANOVA). The hanging test was performed in four separate trials two days after the rotating rod test, and this test did not detect any differences between the two groups (Fig. 1B).

The cliff avoidance test was subsequently performed at six weeks of age. The elevated transparent platform consisted of the base of an inverted glass beaker with a height more than twice the animal's body length. Eight of the fifteen control mice that were placed on an elevated transparent platform avoided the edge of the platform and did not jump off, whereas eleven of the fifteen DE exposed mice jumped off the platform within $10 \mathrm{~min}$. We found differences in the time latency to jump off the platform between the two groups in that the DE-exposed mice jumped off the inverted beaker earlier than the control mice $(\mathrm{P}=0.036)$ (Fig. 2).

\section{Neurochemical analysis}

The brain samples were obtained immediately after the cliff avoidance test, and the levels of monoamine and their metabolites were examined in various brain regions in mice. In the noradrenergic system, prenatal exposure to DE altered the concentration of NA metabolites in the cerebellum of both three- and six-week-old male offspring. Fetal exposure to DE decreased the concentration of MHPG at three weeks of age $(P=0.013$, Fig. 3A), and decreased MHPG and NM concentrations at six weeks of age (MHPG; $\mathrm{P}=0.031, \mathrm{NM}$; $\mathrm{P}=0.007$, Fig. 3B). NA turnover is an index of NA neuronal activity that is calculated as a ratio of NA metabolites to NA, and we found that NA turnover was decreased by maternal exposure to DE (MHPG/NA; P = 0.002, Fig. 3C) (MHPG/NA; $\mathrm{P}=0.015, \mathrm{NM} / \mathrm{NA} ; \mathrm{P}=0.003$, Fig. 3D). The NA concentration in the hypothalamus was not altered at three weeks of age (Fig. 4A), and was dramatically increased in DEexposed mice at six weeks of age $(\mathrm{P}=0.043$, Fig. 4B).

Similar to our previous reports (Yokota et al., 2009; Suzuki et al., 2010), we detected decreased DA metabolites in the nucleus accumbens in DE-exposed male offspring (three-week-old, data not shown) in the dopamin- 
Fetal exposure to diesel exhaust affects behavior in male mice

(A)

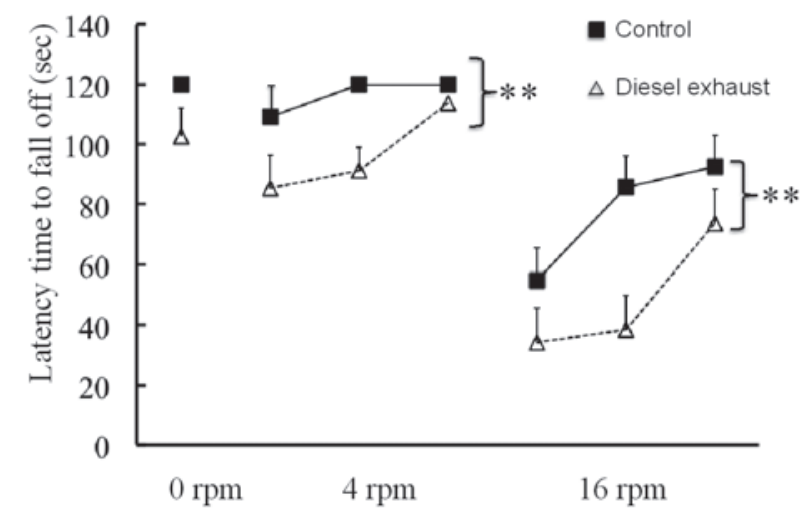

(B)

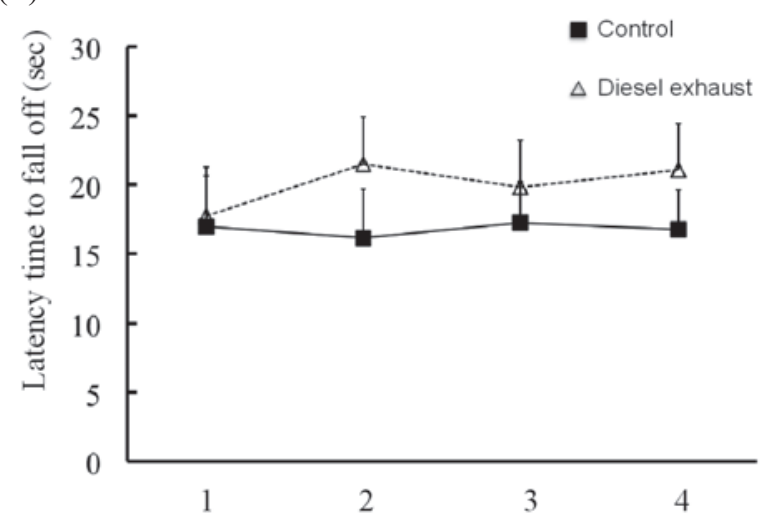

Fig. 1. Evaluation of motor function in the rotating rod test and the hanging test. (A) Retention time of control and maternally exposed diesel exhaust groups on the rotating rod at speed $0 \mathrm{rpm}, 4 \mathrm{rpm}$, and $16 \mathrm{rpm}$. Mice that were maternally exposed to diesel showed decreased time on the rotating rod at $4 \mathrm{rpm}$ and $16 \mathrm{rpm}$. The data represents time course changes in control and the maternally exposed diesel exhaust group. (B) Hanging time of control and maternally exposed diesel exhaust groups. No differences were detected between the two groups. Solid squares and triangles represent control and maternally exposed diesel exhaust mice $(\mathrm{n}=15)$, respectively. Values are mean \pm S.E. $\left({ }^{*} \mathrm{P}<0.05\right.$, $\left.{ }^{* *} \mathrm{P}<0.01\right)$.

ergic system. DA and a DA metabolite, 3-MT, were decreased in the prefrontal cortex in DE-exposed mice at three weeks of age (DA; P $=0.034,3-\mathrm{MT} ; \mathrm{P}=0.041$, Fig. 5A), but not changed at six weeks of age (Fig. 5B). In contrast, we found that DA levels were increased in DE-exposed mice at six weeks of age in the amygdala, and its metabolites were also increased at both three and six weeks of age (DA; $\mathrm{P}=0.028$, DOPAC; $\mathrm{P}=0.008$, HVA; $\mathrm{P}=0.011$, 3-MT; $\mathrm{P}=0.023$, Fig. $5 \mathrm{C})$ (DOPAC; $P=0.012$, Fig. 5D).

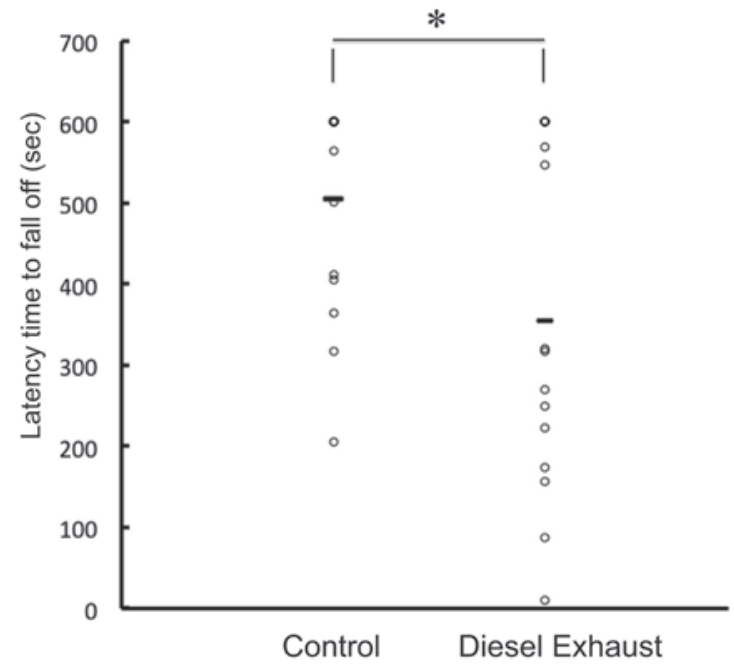

Fig. 2. Evaluation of impulsive behavior in the cliff avoidance test. Maternally exposed disesel exhaust mice tended to explore the corner of the inverted beaker which resulted in jumping off the inverted beaker. Significant differences were detected in cliff avoidance behavior between control and maternally exposed diesel exhaust mice. The data were expressed as scatter plot of latency to jump off within $10 \mathrm{~min}$ in control and diesel exhaust exposed groups. Mice that stayed on the inverted glass beaker were shown as $600 \mathrm{sec}$. Each black bar represents the mean latency to jump off the inverted glass beaker ( $\mathrm{n}=15 ;{ }^{*} \mathrm{P}<0.05$ vs. control group).

In the serotonergic system, we found that prenatal exposure to DE increased 5-HT and 5-HIAA levels in the amygdala at three weeks of age (Table 2). At six weeks of age, an increase was detected in the prenatal DE exposure group in 5-HT and 5-HIAA concentrations in the prefrontal cortex and hypothalamus, respectively (Table 3 ).

\section{DISCUSSION}

The results of the present study indicate for the first time that maternal exposure to DE affects motor coordination and impulsive behavior in mice. In addition, this study demonstrates neurochemical alterations in specific brain regions related to these behavioral deficits. In the present study, DE concentrations were approximately 10 times higher than realistic concentrations. However, the DE concentrations were not so high when lifespan is taken into account, given that mice were only exposed in the fetal period. Only male offspring mice were used in this study due to the variations associated with hormonal imbalance during the estrous cycle seen in female mice. 
S. Yokota et al.
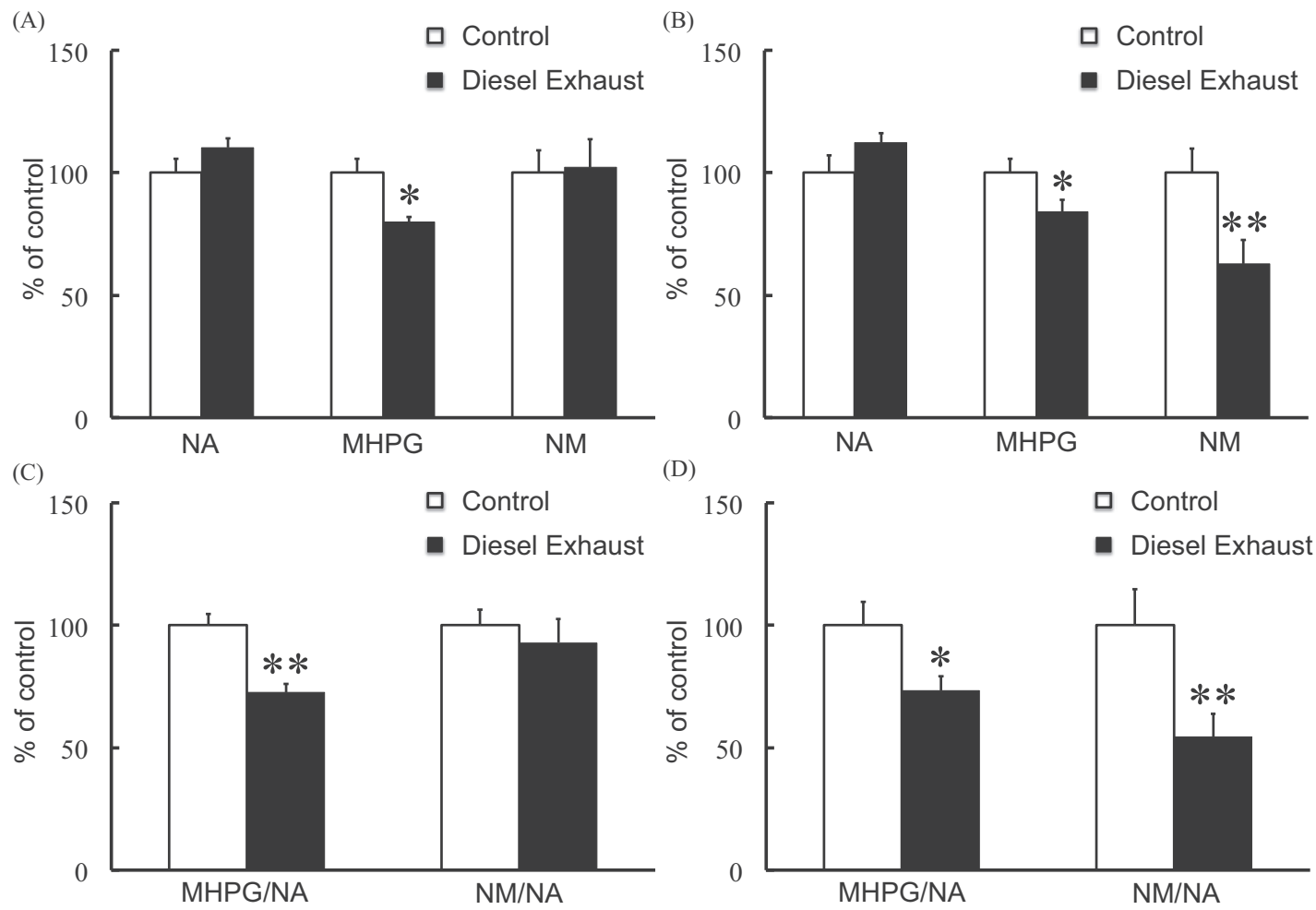

Fig. 3. Levels of noradrenaline and its metabolites in the cerebellum. (A, B) Levels of NA and its metabolites in the cerebellum at (A) three and (B) six weeks old of age. The data were expressed as a percentage of the value in control mice. Each column represents the mean \pm S.E. of nine mice $\left({ }^{*} \mathrm{P}<0.05,{ }^{* *} \mathrm{P}<0.01\right.$ vs. control group). (C, D) Measurement of NA turnover in the cerebellum at (C) three and (D) six weeks old of age. The data were expressed as a percentage of the value in control mice. Each column represents the mean \pm S.E. of nine mice $\left({ }^{*} \mathrm{P}<0.05,{ }^{* *} \mathrm{P}<0.01\right.$ vs. control group $)$. Abbreviations: NA, noradrenaline; MHPG, 4-hydroxy-3-methoxyphenylglycol hemipiperazinium; NM, normetanephrine hydrochloride.

First, we found that prenatal DE exposure decreased the time latency to fall off in the rotating rod test, but did not alter the time latency to fall off in the hanging test. The cerebellum is important for regulation of motor coordination; higher order motor function (Shimizu et al., 2002). It is possible that prenatal exposure to DE affected motor coordination that was specific to parts of the CNS such as the cerebellum, but not components of the periphery such as the skeletal muscle. The results indicated that the concentration of NA metabolites and NA turnover in the cerebellum were decreased by the matenal exposure to DE at three and six weeks of age. The cerebellum, especially Purkinje cells, is important to the modulation of motor coordination and motor learning tasks regulated by gamma aminobutyric acid (GABA) neuron activity (Mitoma and Konishi, 1999). Previous studies indicate that the cerebellum receives widespread nerve terminal projections from noradrenergic neurons (Watson and McElligott, 1984). GABAergic neurons in the Purkinje cells are stimulated by NA neurons to elicit a prolonged inhibition of Purkinje cell activity (Mitoma and Konishi, 1999). A previous study showed that the number of caspase 3 positive cells in the Purkinje cells were significantly increased in maternally DE exposed mice (Sugamata et al., 2006b). In addition, it was reported that vincristine caused massive apoptosis in the cerebellum with caspase 3-like protease activation, which was associated with motor dysfunction in the rotating rod test (Shimizu et al., 2002). It was quite possible that the impairment seen in the rotating rod test following maternal DE exposure may be caused by a reduction in the activity of noradrenergic systems in the cerebellum.

The cliff avoidance test showed that maternal exposure to DE affected impulsive behavior of offspring under novel environmental stress. Impulsive behavior is related to various psychological factors such as social and environmental stress (Matsuoka et al., 2005). In addition, prenatal exposure to DE also affected the concentration of NA 
Fetal exposure to diesel exhaust affects behavior in male mice

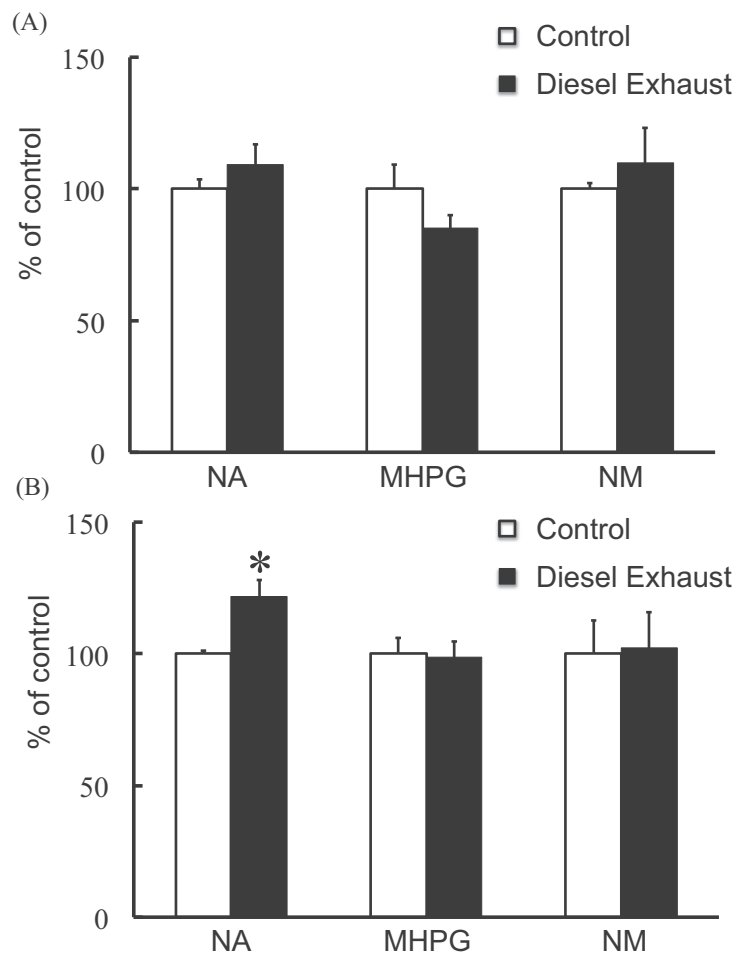

Fig. 4. Levels of noradrenaline and its metabolites in the hypothalamus. (A, B) Levels of NA and its metabolites in the hypothalamus at (A) three and (B) six weeks of age. The data were expressed as a percentage of the value in control mice. Each column represents the mean \pm S.E. of nine mice $\left({ }^{*} \mathrm{P}<0.05\right.$ vs. control group). Abbreviations: NA, noradrenaline; MHPG, 4-hydroxy-3-methoxyphenylglycol hemipiperazinium; NM, normetanephrine hydrochloride.

in the hypothalamus, and these results suggest that DE may represent a stressor when exposed to mouse fetuses. The hypothalamus receives rich noradrenergic innervation from the brainstem, and secretes adrenocorticotropic hormone due to the noradrenergic input (Szafarczyk et al., 1987, 1988). Moreover, intracerebral administration of NA into the paraventricular nucleus, a part of the hypothalamus, also results in an activation of the stress axis (Itoi et al., 1994). On the contrary, noradrenergic antagonists can block stress axis activation. These findings confirm the importance of NA in stimulating corticotropin releasing hormone neurons, which stimulate corticosterone secretion from the adrenal gland into blood (Handa et al., 1994). It was previously reported that prenatal exposure to endocrine disrupting compounds during development affects the hypothalamo-pituitary-adrenal
(HPA) axis (Diamanti-Kandarakis et al., 2009). Furthermore, DE and DEP were also reported to elicit hormonelike activity (Takeda et al., 2004). Therefore, the alteration of impulsive behavior in the prenatal DE exposure group may be mediated by hypothalamic impairment, which is induced by HPA axis activation as well as hormone-like reactions of some DE components.

Understanding the critical periods associated with the effects of DE exposure on the CNS is very important. Previous studies indicate that stimulation or insult at critical phases of CNS development can result in long-term changes in brain structure and function due to neural plasticity via gene-environmental interactions. For instance, the serotonin system in the CNS is well known to be affected by perinatal environmental alterations (Van den Hove et al., 2011). In the present study, we evaluated serotonergic systems of various brain regions in male offspring following maternal DE exposure. At three weeks of age, increased levels of 5-HT and 5-HIAA were observed in the amygdala, and increases in 5-HT and 5-HIAA levels were observed in the prefrontal cortex and hypothalmus at six weeks of age, respectively. Serotonin-based activity propagates from neurons located in the raphe nuclei of the brainstem, the most primitive part of the brain. Therefore, the serotonergic systems are involved in fundamental aspects of physiology including body temperature control, cardiovascular activity as well as respiration, and this system also regulates motor control as well as higher order behaviors, such as impulsive behavior and depressive like behavior (Chase and Murphy, 1973). The broad range of physiology and behavior asociated with the serotonin nerve systems can be attributed to the widespread distribution of serotonin-containing nerve fiber terminals that arise from the raphe nucei. Indeed, the branching of the serotonin network comprises the most expansive neurochemical system in the brain. In our previous study, we found that maternal exposure to DE increased serum testosterone levels in adulthood, which is related to aggressive behavior (Yoshida et al., 2006). A strong relationship between serotonin and testosterone has also been reported in the literature (Birger et al., 2003). The alteration of the serotonin nervous system by maternal exposure to DE may contribute changes in impulsive behavior. However, contradictory findings have been reported regarding the reduction in serotonin concentration and impulsive behavior such as aggression (Birger et al., 2003). Therefore, further investigation is necessary to examine the effects of prenatal exposure to DE on the serotonergic systems and impulsive behavior.

In the present study, the dopaminergic system was investigated in prenatally DE-exposed mice at both three 
S. Yokota et al.
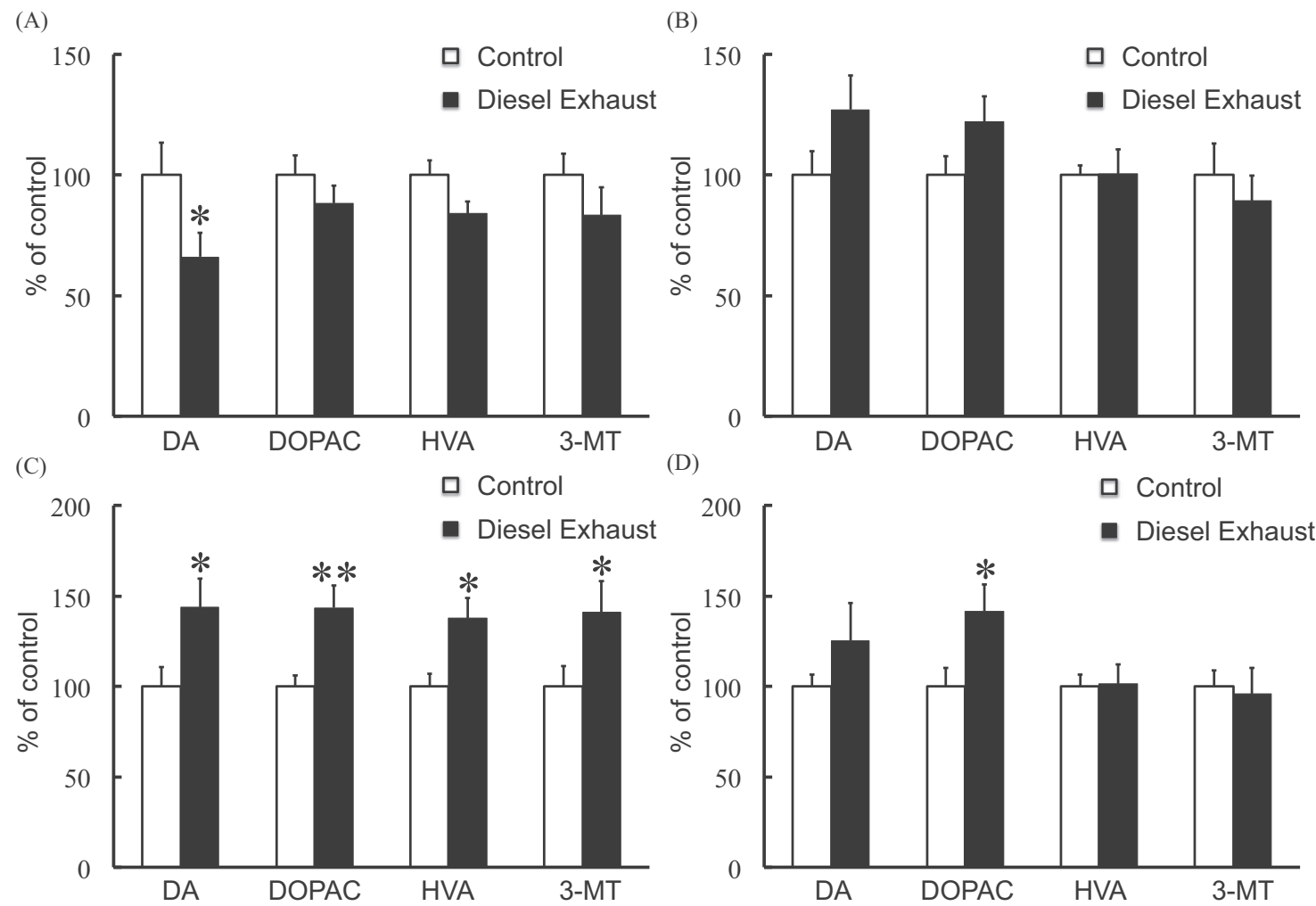

Fig. 5. Levels of dopamine and its metabolites in the prefrontal cortex and the amygdala. (A, B) Levels of DA and its metabolites in the prefrontal cortex at (A) three and (B) six weeks of age. The data were expressed as a percentage of the value in control mice. Each column represents the mean \pm S.E. of nine mice $\left({ }^{*} \mathrm{P}<0.05\right.$ vs. control group). (C, D) Levels of DA and its metabolites in the amygdala at (C) three and (D) six weeks of age. The data were expressed as a percentage of the value in control mice. Each column represents the mean \pm S.E. of nine mice $\left({ }^{*} \mathrm{P}<0.05\right.$ vs. control group $)$. Abbreviations: DA, dopamine; DOPAC, 3,4-dihydroxyphenylacetic acid; HVA, homovanillic acid, 3-MT, 3-methoxytyramine hydrochloride.

and six weeks of age. We found a decrease in DA and its metabolite in the prefrontal cortex of DE-exposed mice (three-week-old), whereas we detected an increase in DA and its metabolite in the amygdala of DE-exposed mice (three- and six-week-old). We previously observed a distribution of DEP in the prefrontal cortex and striatum in adult offspring mice in adulthood (Sugamata et al., 2006a). The direct toxicity of DEP on the DA neuron was reported in an in vitro study that demonstrated that DEP induces DA neuron damage (Block et al., 2004). These findings suggest that inhaled DEP entered the fetal brain accumulating in the prefrontal cortex and striatum, ultimately resulting in DA neuron damage in these brain regions and a reduction in DA and its metabolites. However, DEP accumulation was not detected in the amygdala of offspring mice that were prenatally-exposed to DE. These findings suggest that the mechanism of toxicity associated with maternally inhaled DE may be due to direct or indirect action of DEP. Our unpublished data showed that prenatal exposure to DE affected the CNS more seriously than that of filtered DE, which removes small nano-sized DEP from the exhaust with a filter. We previously reported that the inhalation toxicity of $\mathrm{DE}$ on androgenesis during the fetal period was reduced by filtering and cutting off DEP (Ono et al., 2008). These observations suggest the possibility that surface chemical compounds such as PAH and estrogen around the DEP may affect the CNS of offspring mice. Further investigation will be required to trace DEP in order to identify the various neural cells that incorporate DEP. This study would lead to a better understanding of the precise mechanism associated with how DEP affects motor coordination and impulsive behavior.

In conclusion, in the present study, we showed that prenatal exposure to DE affected motor coordination and impulsive behavior of male offspring mice. In addition, 
Fetal exposure to diesel exhaust affects behavior in male mice

Table 2. Maternal exposure to diesel exhaust changes serotonergic systems in offsprings at three weeks of age

\begin{tabular}{|c|c|c|c|c|}
\hline \multirow{2}{*}{ Brain region } & \multirow{2}{*}{ Group } & \multicolumn{2}{|c|}{ Concentration (pg/mg protein) } & \multirow{2}{*}{$\frac{\text { Turnover }}{\text { 5-HIAA/5-HT }}$} \\
\hline & & $5-\mathrm{HT}$ & 5-HIAA & \\
\hline \multirow[t]{2}{*}{ Prefrontal cortex } & Control & $6692 \pm 543$ & $3520 \pm 243$ & $0.54 \pm 0.03$ \\
\hline & Exposed & $6711 \pm 561$ & $3509 \pm 225$ & $0.53 \pm 0.02$ \\
\hline \multirow[t]{2}{*}{ Striatum } & Control & $6110 \pm 320$ & $6384 \pm 162$ & $1.07 \pm 0.05$ \\
\hline & Exposed & $6830 \pm 403$ & $7035 \pm 278$ & $1.05 \pm 0.04$ \\
\hline \multirow[t]{2}{*}{ Hippocampus } & Control & $4910 \pm 167$ & $5507 \pm 228$ & $1.12 \pm 0.03$ \\
\hline & Exposed & $4733 \pm 286$ & $5120 \pm 292$ & $1.10 \pm 0.04$ \\
\hline \multirow[t]{2}{*}{ Amygdala } & Control & $10888 \pm 490$ & $5654 \pm 168$ & $0.52 \pm 0.02$ \\
\hline & Exposed & $15426 \pm 863 * *$ & $7568 \pm 466^{* *}$ & $0.49 \pm 0.01$ \\
\hline \multirow[t]{2}{*}{ Hypothalamus } & Control & $16168 \pm 547$ & $9625 \pm 291$ & $0.60 \pm 0.01$ \\
\hline & Exposed & $18831 \pm 1251$ & $11458 \pm 712$ & $0.61 \pm 0.02$ \\
\hline \multirow[t]{2}{*}{ Cerebellum } & Control & $1448 \pm 138$ & $1633 \pm 102$ & $1.17 \pm 0.07$ \\
\hline & Exposed & $1988 \pm 421$ & $1691 \pm 95$ & $1.01 \pm 0.09$ \\
\hline \multirow[t]{2}{*}{ Brainstem } & Control & $15369 \pm 573$ & $10437 \pm 400$ & $0.68 \pm 0.02$ \\
\hline & Exposed & $16126 \pm 724$ & $10948 \pm 336$ & $0.68 \pm 0.02$ \\
\hline
\end{tabular}

The data were presented as the mean \pm S.E. of nine mice $(* \mathrm{P}<0.05, * * \mathrm{P}<0.01$ vs. control group).

Table 3. Maternal exposure to diesel exhaust changes serotonergic systems in offsprings at six weeks of age

\begin{tabular}{|c|c|c|c|c|}
\hline \multirow{2}{*}{ Brain region } & \multirow{2}{*}{ Group } & \multicolumn{2}{|c|}{ Concentration (pg/mg protein) } & \multirow{2}{*}{$\frac{\text { Turnover }}{\text { 5-HIAA/5-HT }}$} \\
\hline & & $5-\mathrm{HT}$ & 5-HIAA & \\
\hline \multirow[t]{2}{*}{ Prefrontal cortex } & Control & $6630 \pm 426$ & $2973 \pm 150$ & $0.45 \pm 0.01$ \\
\hline & Exposed & $8686 \pm 516^{*}$ & $3493 \pm 223$ & $0.41 \pm 0.03$ \\
\hline \multirow[t]{2}{*}{ Striatum } & Control & $8530 \pm 382$ & $7309 \pm 667$ & $0.86 \pm 0.07$ \\
\hline & Exposed & $8615 \pm 346$ & $6376 \pm 636$ & $0.74 \pm 0.07$ \\
\hline \multirow[t]{2}{*}{ Hippocampus } & Control & $8096 \pm 496$ & $8061 \pm 653$ & $0.99 \pm 0.05$ \\
\hline & Exposed & $8315 \pm 551$ & $9022 \pm 625$ & $1.09 \pm 0.04$ \\
\hline \multirow[t]{2}{*}{ Amygdala } & Control & $11861 \pm 948$ & $5381 \pm 476$ & $0.45 \pm 0.01$ \\
\hline & Exposed & $11020 \pm 307$ & $5136 \pm 153$ & $0.47 \pm 0.02$ \\
\hline \multirow[t]{2}{*}{ Hypothalamus } & Control & $17518 \pm 410$ & $8544 \pm 355$ & $0.49 \pm 0.01$ \\
\hline & Exposed & $19143 \pm 731$ & $11559 \pm 697 * *$ & $0.61 \pm 0.04^{*}$ \\
\hline \multirow[t]{2}{*}{ Cerebellum } & Control & $3470 \pm 533$ & $2165 \pm 303$ & $0.64 \pm 0.04$ \\
\hline & Exposed & $2736 \pm 431$ & $1960 \pm 166$ & $0.79 \pm 0.07$ \\
\hline \multirow[t]{2}{*}{ Brainstem } & Control & $13395 \pm 435$ & $8517 \pm 538$ & $0.63 \pm 0.03$ \\
\hline & Exposed & $14436 \pm 466$ & $9092 \pm 518$ & $0.63 \pm 0.03$ \\
\hline
\end{tabular}

The data were presented as the mean \pm S.E. of nine mice $(* \mathrm{P}<0.05$, $* * \mathrm{P}<0.01$ vs. control group).

we found that maternal DE exposure altered the monoaminergic systems in various brain regions in male offspring at both three and six weeks of age. The monoaminergic system plays an important role in regulating behavior and maintenance of the CNS. These results provide novel and significant information regarding the health effects of DE and DEP, and further confirm the need to remove DEP from the environment in order to avoid the risk of exposure. 


\section{ACKNOWLEDGMENTS}

The authors would like to thank Dr. Isamu Sugawara and Mr. Tadashi Udagawa (Research Institute of Tuberculosis, Japan Anti Tuberculosis Association, Tokyo, Japan) for help with the diesel exhaust exposure system. We also would like to thank Dr. Masao Sugamata and Dr. Tomomi Ihara of the Tochigi Institute of Clinical Pathology, Dr. Ken Tachibana of Tokyo University of Science, Dr. Seiichi Yoshida of Oita University of Nursing and Health Sciences, and Dr. Naomi Tsukue of the Japan Automobile Research Institute for valuable discussion. This work was supported by Grant-in-Aid for JSPS Fellows (Satoshi Yokota, 22. 5895) and in part by a Grant-in-Aid for Science Research from the Ministry of Education, Culture, Sports, Science and Technology of Japan. This work was also supported by a Grant-in Aid for the Private University Science Research Upgrade Promotion Business “Academic Frontier Project, a Grantin Aid for Health and Labour Sciences Research Grants, Research on Risk of Chemical Substances, from the Ministry of Health, Labour and Welfare" and a Grant-in Aid for NEXT-Supported Program for the Strategic Research Foundation at Private Universities, 2011-2015.

\section{REFERENCES}

Ball, J.C., Straccia, A.M., Young, W.C. and Aust, A.E. (2000): The formation of reactive oxygen species catalyzed by neutral, aqueous extracts of NIST ambient particulate matter and diesel engine particles. J. Air Waste Manag. Assoc., 50, 1897-1903.

Birger, M., Swartz, M., Cohen, D., Alesh, Y., Grishpan, C. and Kotelr, M. (2003): Aggression: the testosterone-serotonin link. Isr. Med. Assoc. J., 5, 653-658.

Block, M.L. and Calderón-Garcidueñas, L. (2009): Air pollution: mechanisms of neuroinflammation and CNS disease. Trends. Neurosci., 32, 506-516.

Block, M.L., Wu, X., Pei, Z., Li, G., Wang, T., Qin, L., Wilson, B., Yang, J., Hong, J.S. and Veronesi, B. (2004): Nanometer size diesel exhaust particles are selectively toxic to dopaminergic neurons: the role of microglia, phagocytosis, and NADPH oxidase. FASEB. J., 18, 1618-1620.

Calderón-Garcidueñas, L., Azzarelli, B., Acuna, H., Garcia, R., Gambling, T.M., Osnaya, N., Monroy, S., DEL Tizapantzi, M.R., Carson, J.L., Villarreal-Calderon, A. and Rewcastle, B. (2002): Air pollution and brain damage. Toxicol. Pathol., 30, 373-389.

Campen, M.J., Lund, A.K., Knuckles, T.L., Conklin, D.J., Bishop, B., Young, D., Seilkop, S., Seagrave, J., Reed, M.D. and McDonald, J.D. (2010): Inhaled diesel emissions alter atherosclerotic plaque composition in ApoE(-/-) mice. Toxicol. Appl. Pharmacol., 242, 310-317.

Chase, T.N. and Murphy, D.L. (1973): Serotonin and central nervous system function. Annu. Rev. Pharmacol., 13, 181-197.

Diamanti-Kandarakis, E., Bourguignon, J.P., Giudice, L.C., Hauser, R., Prins, G.S., Soto, A.M., Zoeller, R.T. and Gore, A.C. (2009): Endocrine-disrupting chemicals: an Endocrine Society scientific statement. Endocr. Rev., 30, 293-342.

George, Xu, Umezawa, M. and Takeda, K. (2009): Early Development Origins of Adult Disease Caused by Malnutrition and Environmental Chemical Substances. J. Health Sci., 55. 11-19.

Gnoth, C., Bremme, M., Klemm, R., Frank-Herrmann, P., Godehardt, E. and Freundl, G. (1999): Research and quality control in natural family planning with relational database systems. Adv. Contracept., 15, 375-380.

Handa, R.J., Nunley, K.M., Lorens, S.A., Louie, J.P., McGivern, R.F. and Bollnow, M.R. (1994): Androgen regulation of adrenocorticotropin and corticosterone secretion in the male rat following novelty and foot shock stressors. Physiol. Behav., 55, $117-$ 124.

Heffner, T.G., Hartman, J.A. and Seiden, L.S. (1980): A rapid method for the regional dissection of the rat brain. Pharmacol. Biochem. Behav., 13, 453-456.

Heinrich, U., Fuhst, R., Rittinghausen, S., Creutzenberg, O., Bellmann, B., Koch, W. and Levsen, K. (1995): Chronic inhalation exposure of wistar rats and two different strains of mice to diesel engine exhaust, carbon black, and titanium dioxide. Inhalation Toxicol., 7, 533-556.

Hougaard, K.S., Jensen, K.A., Nordly, P., Taxvig, C., Vogel, U., Saber, A.T. and Wallin, H. (2008): Effects of prenatal exposure to diesel exhaust particles on postnatal development, behavior, genotoxicity and inflammation in mice. Part. Fibre Toxicol., 5, 3.

Ichinose, T., Yajima, Y., Nagashima, M., Takenoshita, S., Nagamachi, Y. and Sagai, M. (1997): Lung carcinogenesis and formation of 8-hydroxy-deoxyguanosine in mice by diesel exhaust particles. Carcinogenesis, 18, 185-192.

Itoi, K., Suda, T., Tozawa, F., Dobashi, I., Ohmori, N., Sakai, Y., Abe, K. and Demura, H. (1994): Microinjection of norepinephrine into the paraventricular nucleus of the hypothalamus stimulates corticotropin-releasing factor gene expression in conscious rats. Endocrinology, 135, 2177-2182.

Kilburn, K.H. (2000): Effects of diesel exhaust on neurobehavioral and pulmonary functions. Arch. Environ. Health, 55, 11-17.

Landrigan, P.J., Sonawane, B., Butler, R.N., Trasande, L., Callan, R. and Droller, D. (2005): Early environmental origins of neurodegenerative disease in later life. Environ. Health Perspect., 113, 1230-1233.

Matsui, Y., Sakai, N., Tsuda, A., Terada, Y., Takaoka, M., Fujimaki, H. and Uchiyama, I. (2009): Tracking the pathway of diesel exhaust particles from the nose to the brain by X-ray florescence analysis. Spectrochimica. Acta. Part. B., 64, 796-801.

Matsuoka, Y., Furuyashiki, T., Yamada, K., Nagai, T., Bito, H., Tanaka, Y., Kitaoka, S., Ushikubi, F., Nabeshima, T. and Narumiya, S. (2005): Prostaglandin E receptor EP1 controls impulsive behavior under stress. Proc. Natl. Acad. Sci. USA, 102, 16066-16071.

McEwen, B.S. and Alves, S.E. (1999): Estrogen actions in the central nervous system. Endocr. Rev., 20, 279-307.

Mitoma, H. and Konishi, S. (1999): Monoaminergic long-term facilitation of GABA-mediated inhibitory transmission at cerebellar synapses. Neuroscience, 88, 871-883.

Nel, A., Xia, T., Mädler, L. and Li, N. (2006): Toxic potential of materials at the nanolevel. Science, 311, 622-627.

Oberdörster, G., Oberdörster, E. and Oberdörster, J. (2005): Nanotoxicology: an emerging discipline evolving from studies of ultrafine particles. Environ. Health. Perspect., 113, 823-839.

Ono, N., Oshio, S., Niwata, Y., Yoshida, S., Tsukue, N., Sugawara, I., Takano, H. and Takeda, K. (2008): Detrimental effects of pre- 
Fetal exposure to diesel exhaust affects behavior in male mice

natal exposure to filtered diesel exhaust on mouse spermatogenesis. Arch. Toxicol., 82, 851-859.

Paxinos, G. and Franlin, K.B.J. (2001): The mouse brain in stereotaxic coordinates. Academic Press, 2.

Pope, C.A. 3rd. (2004): Air pollution and health-good news and bad. N. Engl. J. Med., 351, 1132-1134.

Santodonato, J. (1997): Review of the estrogenic and antiestrogenic activity of polycyclic aromatic hydrocarbons: relationship to carcinogenicity. Chemosphere, 34, 835- 848.

Shimizu, H., Ohgoh, M., Momose, Y., Nishizawa, Y. and Ogura, H. (2002): Massive cell death of cerebellar granule neurons accompanied with caspase-3-like protease activation and subsequent motor discoordination after intracerebroventricular injection of vincristine in mice. Neuroscience, 115, 55-65.

Sugamata, M., Ihara, T., Takano, H., Oshio, S. and Takeda, K. (2006a): Maternal diesel exhaust exposure damages newborn murine brains. J. Health Sci., 52, 82-84.

Sugamata, M., Ihara, T., Sugamata, M. and Takeda, K. (2006b): Maternal exposure to diesel exhaust leads to pathological similarity to autism in newborns. J. Health Sci., 52, 486-488.

Suzuki, T., Oshio, S., Iwata, M., Saburi, H., Odagiri, T., Udagawa, T., Sugawara, I., Umezawa, M. and Takeda, K. (2010): In utero exposure to a low concentration of diesel exhaust affects spontaneous locomotor activity and monoaminergic system in male mice. Part. Fibre Toxicol., 7, 7.

Szafarczyk, A., Malaval, F., Laurent, A., Gibaud, R. and Assenmacher, I. (1987): Further evidence for a central stimulatory action of catecholamines on adrenocorticotropin release in the rat. Endocrinology, 121, 883-892.
Szafarczyk, A., Guillaume, V., Conte-Devolx, B., Alonso, G., Malaval, F., Pares-Herbuté, N., Oliver, C. and Assenmacher, I. (1988): Central catecholaminergic system stimulates secretion of CRH at different sites. Am. J. Physiol., 255, E463-468.

Takeda, K., Tsukue, N. and Yoshida, S. (2004): Endocrine-disrupting activity of chemicals in diesel exhaust and diesel exhaust particles. Environ. Sci., 11, 33-45.

Tsukue, N., Watanabe, M., Kumamoto, T., Takano, H. and Takeda, K. (2009): Perinatal exposure to diesel exhaust affects gene expression in mouse cerebrum. Arch. Toxicol., 83, 985-1000.

Umezawa, M. and Takeda, K. (2011): Automobile exhaust: Detrimental effects on pulmonary and extrapulmonary tissues and offspring. "Encyclopedia of Environmental Health", 1, 247-252.

Van den Hove, D.L., Jakob, S.B., Schraut, K.G., Kenis, G., Schmitt, A.G., Kneitz, S., Scholz, C.J., Wiescholleck, V., Ortega, G., Prickaerts, J., Steinbusch, H. and Lesch, K.P. (2011): Differential effects of prenatal stress in 5-Htt deficient mice: towards molecular mechanisms of gene $\times$ environment interactions. PLoS One., 6, e22715.

Yokota, S., Mizuo, K., Moriya, N., Oshio, S., Sugawara, I. and Takeda, K. (2009): Effect of prenatal exposure to diesel exhaust on dopaminergic system in mice. Neurosci. Lett., 449, 38-41.

Yoshida, S., Ono, N., Tsukue, N., Oshio, S., Umeda, T., Takano, H. and Takeda, K. (2006): In utero exposure to diesel exhaust increased accessory reproductive gland weight and serum testosterone concentration in male mice. Environ. Sci., 13, 139-147.

Watson, M. and McElligott, J.G. (1984): Cerebellar norepinephrine depletion and impaired acquisition of specific locomotor tasks in rats. Brain Res., 296, 129-138. 